\title{
Development and Evaluation of Mobile Telenursing System for Drug Administration
}

\author{
Emuoyibofarhe O. Justice \\ Department of Computer Science and Engineering \\ Ladoke Akintola University of Technology, Ogbomoso, Oyo State, Nigeria \\ Email: eojustice@gmail.com
}

\section{Adigun J. Olusegun}

Federal College of Wildlife Management

New Bussa, Niger State, Nigeria

Email: sunkanmisegun@gmail.com

\author{
Emuoyiborfarhe N. Ozichi \\ Department of Computer Science \\ Bowen University, Iwo, Osun State, Nigeria \\ Email: eozichi@yahoo.com
}

Received: 03 November 2019; Accepted: 23 December 2019; Published: 08 August 2020

\begin{abstract}
Mobile telenursing is an emerging sub-field of mobile health that proposes remote nursing care provision with the aim of reducing stress on nurses by enabling them to spend more time on direct patient care rather than indirect care. Most existing mobile telenursing systems are limited to a simple phone call and Short Message Service (SMS) alert thereby rendering them inadequate to support indirect patient cares such as remote prescription based on consultant's advice and monitoring of drug usage adherence. Hence, this research developed a Mobile Telenursing and Drug Administration System (MTS) characterized by support for the aforementioned indirect patient cares. DomainDriven Design was employed in designing MTS client-server architecture and its framework. The framework was implemented by developing an SMS reminder system and client mobile application which maintains real-time communication with the webserver. The MTS, which supports real-time consultation between nurse-patient and nurseconsultant, was developed for mobile devices running the Android operating system using the framework implemented. The MTS was programmed using JavaScript and Pusher real-time messaging library of the Android development Kits. The performance of the MTS was evaluated through users' assessment by administering a set of questionnaire on purposively selected 64 nurses; 53 patients chosen from four (4) purposively selected hospitals (General Hospital, New Bussa; Bowen University Teaching Hospital, Ogbomoso; Alimosho General Hospital, Lagos and Ifako-Ijaiye General Hospital, Lagos). The responses obtained from the questionnaires were statistically evaluated to determine MTS suitability for drug usage monitoring, remote prescription, palliative care, injection administration, patients' clean-up and follow-up treatment using a correlation test. Also, mean effectiveness and mean acceptability of MTS were evaluated using a t-test at 0.05 level of significance. The MTS was deployed on mobile devices running the Android operating system. The results of performance evaluation revealed that MTS recorded suitability values of drug usage monitoring $(r=0.656)$, remote prescription $(r=0.829)$, palliative care $(r=0.925)$, injection administration $(r=-0.772)$, patients' clean-up $(\mathrm{r}=-0.841)$ and follow-up treatment $(\mathrm{r}=0.868)$ of patients at $(\mathrm{p}<0.05)$. Similarly, MTS recorded mean effectiveness and acceptability values of 3.596 and 3.32, 3.770 and 3.36 at $(\mathrm{p}<0.05)$ for nurses and patients, respectively. The research developed MTS which is suitable for the provisioning of remote nursing care and drug administration without breaking basic medical ethics. The system can be adopted for mobile telenursing and drug administration system.
\end{abstract}

Index Terms: Drug usage Adherence, Mobile Health, Mobile Telenursing, Remote Prescription.

\section{Introduction}

The proliferation of mobile applications, mobile devices with wireless capabilities, increasing access to the internet and reduction in the cost of internet access has enabled mobile systems to find increasing applicability. More so, mobile systems possess capabilities that enable their usage in a myriad of applications that could not be sensibly implemented 
on stationary systems, for example, the mobility capability of mobile systems enables them to be used in location tracking. Mobile software applications have therefore been applied to many fields that the traditional computing systems have found applications including the mobile surveillance, mobile news, mobile games, mobile learning, mobile commerce, mobile library, and mobile business and for the purpose of this study mobile health [1].

[3] opined that the lack of access to quality health care is, unfortunately, common realities witnessed by poor and underprivileged in many developing countries, thus, inability to pay for health care expenses forces many people facing health challenges in such countries to either reduce spending on food and other basic needs to concentrate on their nursing care needs or totally neglect their health and be left to the mercies of deteriorating health and untimely death. According to them, the need to improve health care quality, expand access to affordable health care and reduce health care cost is the driving forces for the unprecedented success of mobile health.

Mobile telenursing is a subset of mobile health that allows for the provision of guided patient self-care ubiquitously. Mobile telenursing or simply mobile nursing (mNursing) aids in getting the patient to the right level of care with the right provider in the right place at the right time (AAACN, 2007). Mobile telenursing is the use of mobile technology to provide or support nursing care practice or manage and coordinate nursing care to mobile patients from a distance using a broad range of telecommunication modalities [4]. These, mobile technology and telecommunication modalities include Short Message Service (SMS), MMS, multimedia conferencing, e-alerts, customized internet applications and telemonitoring equipment [1].

Mobile telenursing enables telenurses to carry out some drug administration functions (including obtaining consultant diagnoses and relating the same to the patients, medication usage monitoring, ensuring drug usage adherence) to patients in a ubiquitous and real-time environment. It ensures a reduction in self-medication yet keeps more patients out of hospital thus reducing the stress on the scarce hospital facility at minimal cost to the patients, with better outcomes, decrease in hospitalizations and saving time, etc.

Mobile telenursing presents the possibility of promoting patients' self-care by enabling nurses to divert substantial attention from this responsibility thus increasing nurses' effectiveness in handling the nurse - patients' ratio situation in the nation and reduce rural-urban health care marginalization. To make necessary provisions for the inherent benefit of telenursing in developing countries is, therefore, the need to develop and evaluate the effectiveness of a mobile telenursing system for its suitability to promoting indirect patients' care.

\section{A. Aim and Objectives}

Sequel to [1], this study aims to implement the mobile telenursing system (MTS) and evaluate the effect of telenursing intervention on satisfaction and health outcomes of patients in developing countries. The specific objectives include:

i. To implement the prototype of the MTS software developed on the Android operating system.

ii. To pilot test the prototype of the MTS software developed in strategically selected hospitals

iii. To evaluate the performance of the MTS based on suitability, effectiveness, and acceptability through user experience.

\section{B. Scope of the Study}

Telenursing involves many health practitioners and many nursing functions however; the focus of this research was on indirect patient care of drug administration.

\section{Literature Review}

Previous work by one of the authors and some collaborators, that is, [1] is the etiological starting point for this study. Therein, the authors analyzed and designed the framework of the system to prevent the chain of healthcare delivery from being broken from diagnosis to treatment by allowing trained telenurses collect and screen a patient's health-related symptoms via mobile devices, communicate the same to a more experienced specialist or physician, and communicate the physician's/specialist's advice on the best course of action back to the patients. They went on to analyze and design the required system and describe their proposed implementation of the system modules on the Android operating system. Afterward, they promised to pilot test and evaluate the developed MTS on completion. This paper details the result of pilot testing and evaluating the performance of the MTS as promised.

Other works consulted in the course of this research are reported below:

Some literature that presented issues on telenursing often equates telenursing with telephone triage. Ref. [6] reviewing recent trends, emerging issues, and evolving practices says: "telephone triage and advice services or telenursing, is an evolving model of care delivery facilitated by technology". Ref. [8] presented issues on Patient Safety, Telenursing, and Telehealth. They noted that compliance and adherence problems are among the many issues that necessitate the adoption of telenursing. According to them, after a patient leaves a provider's office or a hospital, the patient is responsible for his or her own health care at home. Patients often do not follow a treatment plan as directed by a physician or provider due to several reasons including miscommunication or non-understanding of the treatment plan, 
lack of access to basic facilities needed for the treatment plan, and a complex treatment regimen difficult for the patient to comprehend without additional guidance. They opined that telemonitoring and telediagnosis is possible by citing the work of [9] that found that the remote interpretation and diagnosis with electrocardiogram results were just as good as interpretation in person. Therefore, they were suggesting that tele drug administration decisions can be made based on the diagnosis results; however, they did not extend their research beyond the nurse-patient situation which allows for telediagnosis, furthermore, they did not build nor analyze the required system.

A winning strategy was developed in the Centre for Psychotherapy Research in Stuttgart, Germany, for the aftertreatment of a patient with Bulimia Nervosa based on SMS. The intervention consists of weekly messages from patients on their bulimic symptomatology and corresponding weekly feedback that is a mixture of pre-programmed parts and individually tailored information. Results indicate that the program is technically feasible, well-accepted by patients and helpful for patients with bulimia nervosa to readjust to everyday life after finishing inpatient treatment [2]. However, the research did not go beyond simple SMS alerts and feedback.

Another success story reported by [5] is the "On Cue" project in South Africa sending SMS reminders to patients with tuberculosis for drug regimen compliance. SMS were sent out every half-hour within a chosen time-frame to remind patients to take medicine. As of January 2003, the city of Cape Town has paid only \$16/patient/year for SMS reminders. In this pilot, only 1 patient out of 138 was non-compliant (99.3\% compliance rate). However, the research too like [2] did not go beyond simple SMS alert and feedback.

Ref. [10] reported on clinical and psychological telemonitoring and telecare of high-risk patients with chronic heart failure through wireless technologies, dedicated software was developed to collect patients' data on a smartphone, PDA, and allow their subsequent wireless transmission to the remote server for storage and analysis. The system was designed to communicate with each patient, asking simple questions about his/her symptoms and giving information and counseling through audio and visual reminders.

The remote control included: a patient front-end, a medical front-end and a software web-based clinical decision and a reminder system. The patient front-end is operated on a PDA that each patient received at discharge from the hospital. At a defined prescheduled time, patients are required to transmit their blood pressure which the cardiologist analyzed, evaluated their clinical priority and could call the patient or send SMS to modify the therapy if great variability was observed, to tailor the timing of drugs' administration, ask more information or recommend a clinical control. The system created a graphic trend of the variables preliminarily chosen by the cardiologist so that a more frequent control could be asked for those that were found more difficult to control (i.e. a patient could be asked to transmit his/her blood pressure twice a day if great variability was observed, to tailor the timing of drugs administered). The telemonitoring device was seen to help in better treatment-adherent. However, the system did not include the role of nurses thereby breaking the chain of healthcare delivery from diagnosis to treatment.

Ref. [7] developed a system that was based on phone calls to monitor satisfaction and health outcomes of children with inflammatory rheumatic diseases using Cox's Interaction Model of Client Health Behavior (IMCHB). IMCHB's conceptual foundations are client singularity (individuals' characteristics), client professional interaction, and health outcomes. This model offers support in determining the optimal way for a nurse to interrelate with a patient to reach positive health outcomes. Its three conceptual foundations are: client singularity (individuals' characteristics), client professional interaction, and health outcomes.

This paper takes telenursing a step beyond [2] and the "On Cue" project reported by [5], and include nurses in the chain of telehealth care delivery reported by Villaini et al. (2013) by developing and evaluating Mobile Telenursing System (MTS) based on the Cox's Interaction Model of Client Health Behaviour (IMCHB) found in Cox (2003). The system which was developed for mobile devices running the Android operating system allows consultation between nurse - patients and nurse - experienced nurse (or specialist). The patients can be reached anywhere, anytime and vital signs on drug administered (adverse effects of drugs, improvement noticed) are being relayed by the patients to the telenurses who then decide on next line of action as pertaining to the drug administration after making necessary consultation which prevents the chain of healthcare delivery from being broken from diagnosis to treatment. The system also included an automated reminder system for reminding patients of drug usage as at when due.

\section{Methodology}

The research employed the experimental methodology in the design of the framework and development of the MTS and employed the quasi-experimental methodology in the evaluation of the system based on the Cox's Interaction Model of Client Health Behaviour (IMCHB).

\section{A. System Analysis and Design}

As earlier stated, this paper is a sequel to [1], hence the design of the system was based on the requirement and specification that has been judiciously analyzed in [1], therefore to focus on the aim of this paper, details of the system analysis and design will not be delved into. 
The stakeholders that were established to be important in the system development life cycle include the care center, the telenurses, and the telepatients and/or their caregivers and consultants/specialists. These stakeholders' interaction is depicted in the use case presented in figure 1.

The care center is the dedicated hospital facility to offering telenursing services being managed by the care center telenurse operator saddled with the extra responsibility of registering patients, assigning telenurses to registered patients at the point of the patients' registration and providing back up services to telenurses as at when needed. The telenurses are nurses that have been trained to nurse patients at a distance. The telepatients are patients receiving tele-treatments from the care center. The consultants include the doctors and/or specialists that the nurses can contact for diagnosis purposes or expert advice whenever needed.

Communication within the system is mainly through the internet, that is, the consultants', care center operator's, mobile patients' and telenurses' mobile devices used the mobile operators' internet services to communicate and internet connectivity through the various mobile operators was required for telecommunication between the stakeholders and the care center server also maintains broadband connectivity to the internet.

The functional and non-functional requirements of the system as gathered from the analysis include:

\section{Functional Requirements}

- Registration of the telenurses and patients is done by the care center operator.

- Both telenurses and patients are given a unique username and password.

- Patients are assigned to telenurses during patients' registration.

- After logging in, patients can read reminder/notification

- Patients can also contact telenurse to relay symptoms and any issues/cases to telenurses.

- After logging in, telenurses can contact a consultant to relay issues that require expert advice to a consultant

- Telenurses can also connect patients to monitor patients to ascertain if there are any/no issues that need attention so as to give them adequate advice.

- Telenurses can also send a drug usage reminder and another form of reminder.

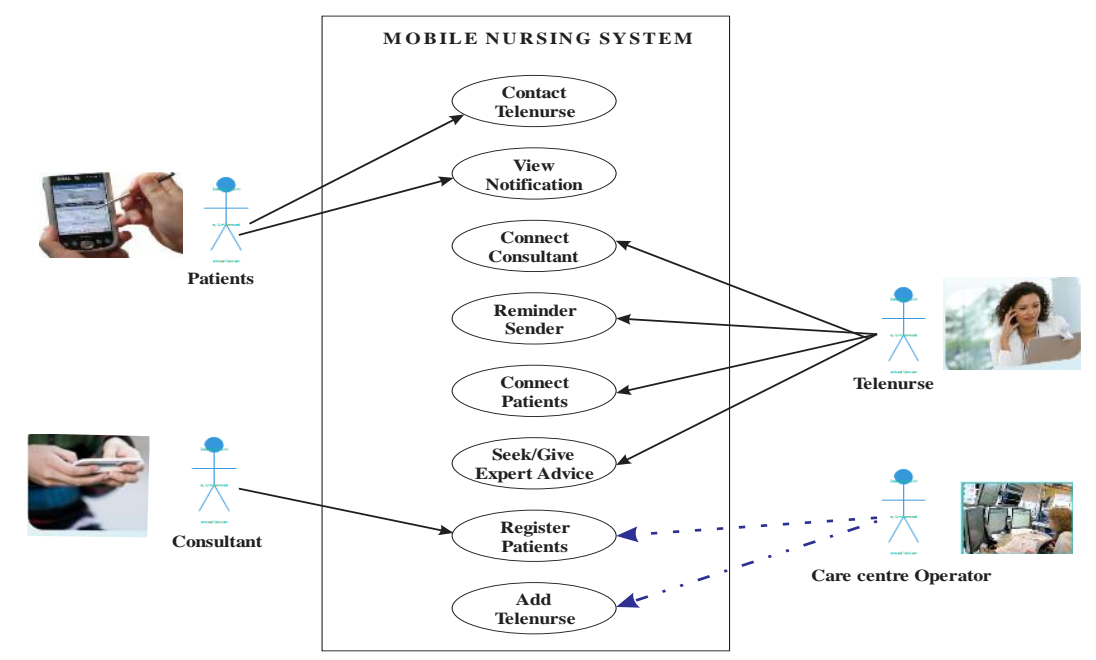

Fig. 1. Use case depicting stakeholders' interaction in the proposed system.

To figure axis labels, use words rather than symbols. Do not label axes only with units. Do not label axes with a ratio of quantities and units. Figure labels should be legible, about 9-point type.

Color figures will be appearing only in an online publication. All figures will be black and white graphs in print publication.

\section{Non Functional Requirements:}

- $\quad 24$ X 7 available text-based chat-like platform that shows chat in real time

- Reliable store and forward multimedia upload platform to communicate visualizations

- $\quad$ Both web and database server that possesses 24 X 7 availability

- Widely used the mobile operating system in the region of deployment

- Efficient assignment of telenurses to patients

- Better component design to get better performance at peak time

- The flexible service-based architecture will be highly desirable for future extension

- Efficient 2G/3G and GSM/GPRS internet connectivity 


\section{B. System Evaluation Methods}

The system performance evaluation was conducted to provide confidence that the developed software solution met both the functional and non-functional requirements by verifying the suitability, effectiveness, and acceptability of the developed system to the users (patients and nurses). The system performance was evaluated from user experience perspective based on the three conceptual foundations of Cox's Interaction Model of Client Health Behaviour (IMCHB) which include client singularity (individuals' characteristics), client professional interaction, and health outcomes of the clients as shown in figure 1. The study utilized the quasi-experimental design to involve prospective users, that is, the clients (telepatients and/or their care givers) and the professionals (telenurses) in the system validation process. The study was based on the following assumptions:

i) The MTS provides ease of access to patients' known allergies and medical history which form part of the client singularity.

ii) The MTS enhances patients' - nurses' interaction

iii) Based on (i) and (ii), the MTS improves the patients' health outcome

Based on the assumptions, the study is guided by the following research hypotheses:

H01: The MTS is not suitable for the provision of mobile telenursing services in the study area.

H02: The MTS is not effective enough to complement the provision of nursing care in the study area.

H03: The MTS is neither usable nor acceptable by the patients and nurses in the study area

\section{Settings and Participants}

The study involves two study groups for telenurses and patients; the experimental and control group for the patients; a pre-test and post-test for the nurses. The control group patients were administered questionnaires without been made to use the developed system while the program group was made to use the developed system for one month by assigning them to a telenurse that provides telecare for them via the developed system. The nurses were first administered the questionnaire before (pre-test) and after (post-test) they were made to use the developed system. The quasi-experiment test/determines whether the provision of mobile telenursing and drug administration system has any significant influence on the responses of the program group (patients) and the nurses' post-tests. The Mobile telenursing Adequacy Questionnaire (MTAQ) was administered to the patients and nurses between September 2016 and January 2017. The criteria presented in Table 1 afforded a high return rate.

Table 1. Respondents' enrolment criteria

\begin{tabular}{|c|c|c|}
\hline & Inclusion Criteria & Exclusion Criteria \\
\hline 1 & $\begin{array}{l}\text { Incidentally met during } \\
\text { experimental period }\end{array}$ & $\begin{array}{l}\text { Non willingness to be part of the } \\
\text { experiment }\end{array}$ \\
\hline 2 & $\begin{array}{l}\text { Currently receiving } \\
\text { treatment at the hospital } \\
\text { during the period }\end{array}$ & $\begin{array}{l}\text { Non possession or inability to } \\
\text { adequately use Android phone } \\
\text { (especially nurses) }\end{array}$ \\
\hline
\end{tabular}

\section{Population, sample and sampling technique}

The study population included nurses and patients from all hospitals in Nigeria. However, for this study, a multistage sampling technique was used to strategically select four hospitals (two hospitals each from the rural and urban areas) in the first stage. The next stage involves the selection of nurses and patients met at the period of conducting the study that indicated interest in being part of the study. The strategy used ensured that the hospitals were selected from both urban and rural areas of the country while the incidental selection implies that the participants such as patients, caregivers and nurses met at the time the research was conducted at the hospitals and those that signified interest in being part of the research work from the strategically selected hospitals were the ones used for the study. United nation differentiation of rural and urban areas classifies urban areas as highly inhabited locality, less traditional, possessing a higher standard of living, thus, the two hospitals from Lagos were chosen as hospitals from urban areas while the hospitals from Ogbomoso and New Bussa were chosen as the ones from rural areas. The lists of hospitals, nurses and patients selected in each of the hospitals are:

i. Alimosho General Hospital, Lagos state (15 nurses, 17 patients)

ii. Ifako-Ijaiye General Hospital, Lagos state ( 9 nurses, 16 patients)

iii. Bowen University teaching hospital, Ogbomoso, Oyo state (25 nurses, 14 patients)

iv. General Hospital, New Bussa, Niger state (6 nurses, 20 patients) 
In all, samples of the research instrument were distributed to fifty-five (55) nurses and sixty-seven (67) patients. Thirty-five (35) of the patients were assigned to the control group while the remaining thirty-two (32) were assigned to the experimental group.

\section{E. Research Instrument}

The research instrument used in this study was a self-constructed Mobile telenursing Adequacy Questionnaire (MTAQ) developed. There are three categories of the MTAQ: Pretest and posttest questionnaire for nurses and questionnaires for patients. Section A of all questionnaire categories contains personal data of the respondents, section $\mathrm{B}$ of the nurses' questionnaire contains data about the level of awareness of the nurses about mobile nursing while section C of the nurses' questionnaire and section B of the patients' questionnaire contains questions that elicit information about the adequacy of the MTS. The questionnaires are in 3- and 5- point Likert.

\section{F. Method of Data Analysis}

The data collected from the participants were analyzed using charts, Pearson correlation statistics, paired sample and independent sample T-Test statistics with the aid of Microsoft Excel and Statistical Package for Social Sciences (SPSS).

\section{Results and Discussions}

\section{A. The Developed System}

The MTS prototype software was developed based on the requirements and specifications. The interface shown in Figure 2 shows all categories of users that can be logged into the system while Figure 3 and Figure 4 show the activities that can be performed by patients and telenurses respectively. The patients can choose from either of:

i. Contact Telenurse: This module was used to relay symptoms and any issues/cases to telenurses.

ii. Notifications: This module, on the other hand, was used to view notifications sent by telenurses.

During login, the care center operator has to check the care center operator checkbox after which the next interface allows the care center operator to select an activity to perform among any of the following:

i. Connect Consultant: This module was used to relay issues that require expert advice to a consultant.

ii. Register Patient: This module was used to register patients and assign each patient to a telenurse at the point of registration.

iii. Connect patient: This module was required by telenurses to monitor a patient's health by contacting them to ascertain if there are any/no issues that need attention so as to give them adequate advice.

iv. Add Telenurse: This module was used to register telenurses' new telenurses.

v. Reminder Sender: This module usage reminder used to send drug usage and patients' educative reminder.

The only difference between activities that can be performed by an assigned telenurse and the telenurse that acts as the care center operator is that the assigned telenurses can neither add patients nor add another telenurse. Figure 5, Figure 6, Figure 7 and Figure 8 depicts some of the activities that involved the telenurses and the patients.

A text-based chat-like platform is displayed which allows the patients to relate whatever symptom he felt to his/her assigned telenurse. The telenurse upon accessing the clinical condition either advise the patients (for a non-severe case) or refer the clinical condition to an available teleconsultant for expert advice (for a severe case) which the telenurse relay back to the patient. In Figure 5, the telenurse upon accessing the patient's clinical condition discovered she required expert advice; hence she contacted a consultant as shown in figure 6 . In figure 7, the telenurse selects the patient he/she wishes to send a notification to sets the date and time to send the reminder (and notification interval), after which he/she composes the drug usage notification and send the notification. The system selects the phone number the patient supplied at the point of registration and sends the notification message as a text message to the patient's phone number which receives the message as shown in figure 8. 


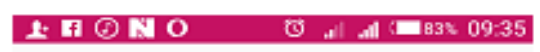

\begin{tabular}{|c|}
\hline CONSULTANT LOGIN \\
\hline TELE NURSE LOGIN \\
\hline PATIENT LOGIN \\
\hline
\end{tabular}

$\square$

$\bigcirc$

$\triangleleft$

Fig. 2. The interface of the MTS showing actions patient can perform

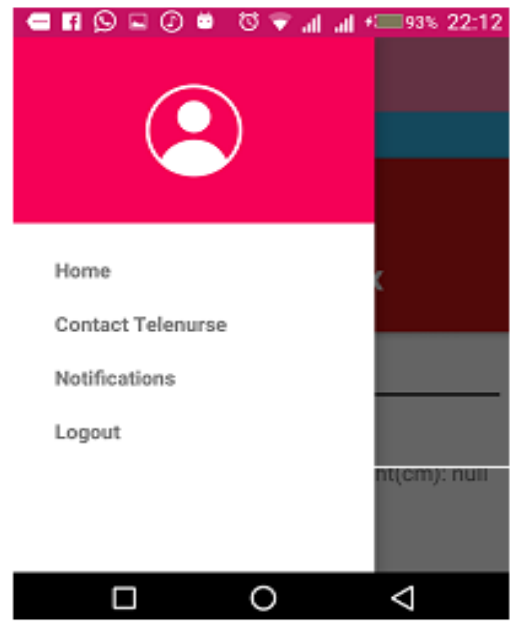

Fig. 3. Interface indicating some activities that can be performed by the patient

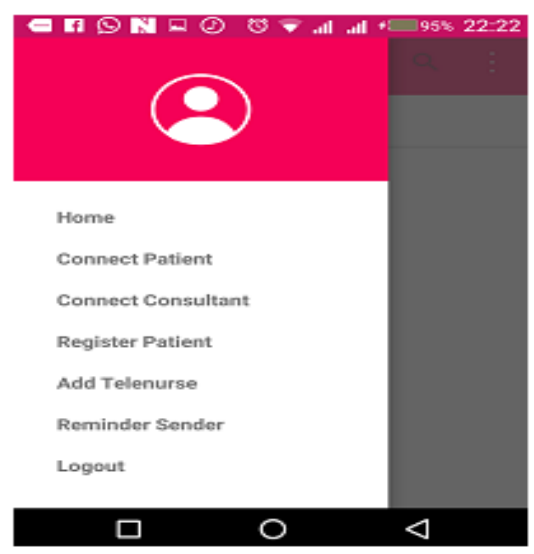

Fig. 4. Interface indicating some activities that can be performed by care center telenurse 


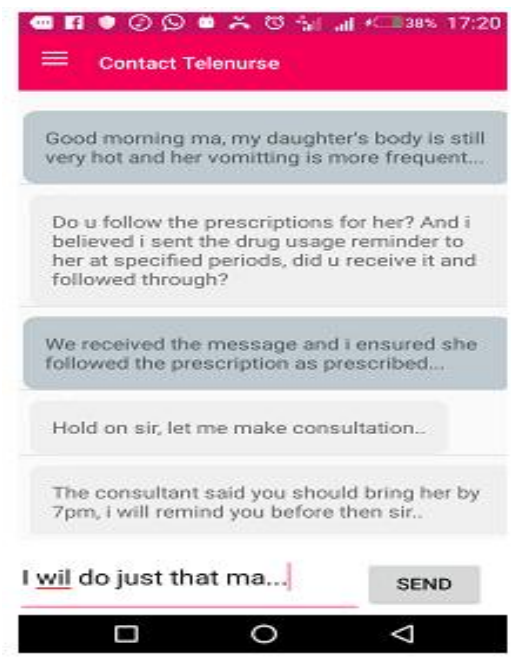

Fig. 5. Caregiver relaying patient's issue with telenurse

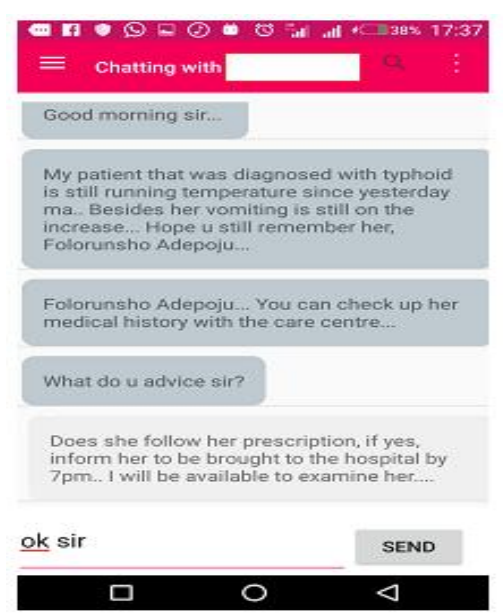

Fig. 6. Telenurse seeking expert advice from a doctor

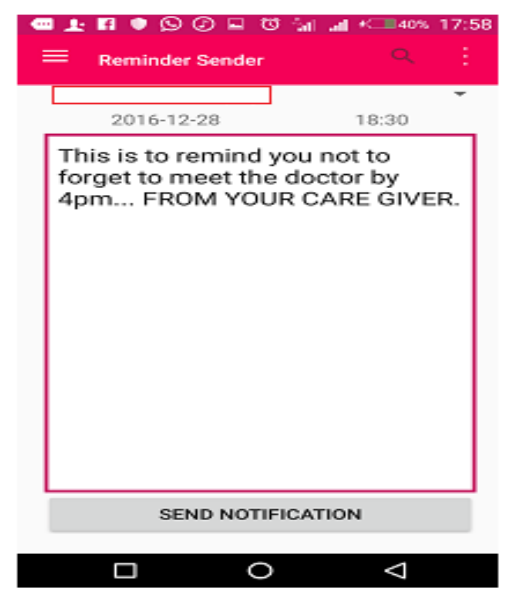

Fig. 7. The patient received an SMS alert from a telenurse 

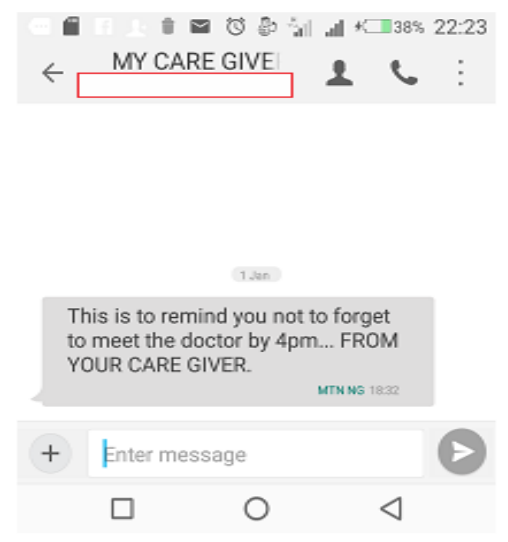

Fig. 8. A telenurse compose drug notification sent to a patientnurse

\section{B. Data Analysis} Table 6.

The adequacy of the use of MTS in terms of suitability, effectiveness, and usability was presented in Table 2 -

Table 2 shows a correlation test performed to test whether or not the developed telenursing drug administration system is suitable to function as an efficient mobile telenursing system.

Table 3 and Table 4 show paired sample t-test and independent sample t-test respectively performed to test whether or not the developed telenursing drug administration system is effective enough to complement the traditional nursing care system.

Table 5 and Table 6 show a paired sample t-test performed to test the ease of usage of the developed mobile telenursing system.

\section{Discussion of findings}

The result of the analysis presented in Table 4.2 shows that the developed MTS was suitable to function as an efficient mobile telenursing system in any capacity including drug usage monitoring, remote nursing care provision, triage, patient's education, palliative care provision, patient's monitoring and after treatment etc. (except for patient's education which was not significant at 0.05 confidence level) because the result of the analysis shows a significant positive correlation ( $\mathrm{p}<0.01$ or $\mathrm{p}<0.05$ and $\mu>0$ ) hence, the nurses were shown to have confidence in the ability of the developed system as being suitable telenursing system to function in the aforementioned capacity in developing countries. However, the developed system was not found suitable for to be used to direct on injection administration and patients clean up as depicted by the significant negative correlation $(\mu<0)$. The overall mean suitability value of 0.837 recorded by the MTS shows that the MTS is generally suitable for telenursing drug administration system in contrast to the work of [8] and [6].

Table 3 and Table 4 show that the developed MTS is an effective complement to traditional nursing care ( $p<0.05$; $\mu>3$ ). Specifically, Table 3 shows an increasing care of patients in all variables (e.g. drug usage adherence, remote nursing care, triage, patient's evaluation, education, monitoring and after treatment, etc.) measured when using MTS compared with non-usage of MTS, also in Table 4, from the patient's perspectives, telenursing intervention was shown to be more effective across all variables as it depicts better care of patients treated with usage of telenursing intervention as compared with those treated without usage of MTS. The overall mean effectiveness values of 3.59 and 3.32 (for nurses and patients respectively) recorded by the MTS on a rating the scale of 1 to 5 was in line with the findings of [10]. It also extended beyond their own limitation as their work did not include the role of nurses thereby breaking the chain of healthcare delivery from diagnosis to treatment.

Table 5 and Table 6 shows that the developed telenursing system beats the expectation of the respondents as pertaining to its ease of usage across all variables measured which made it be acceptable by the nurses. This is depicted by a significant positive mean score $(\mathrm{p}<0.05 ; \mu>0)$ difference in terms of its cost of implementation, training requirement, ease of interpreting patient's clinical condition, allowance for doctor's input during diagnosis, etc. in Table 5. Also, table 6 showed that the patients agreed that the MTS was shown to be acceptable and easy to use across all variables even though the ease of interpretation of nursing care needs and requirement of information technology technical-know-how was not significantly agreed upon. The overall mean acceptability values of 3.770 and 3.36 (for nurses and patients respectively) recorded by the MTS on a rating the scale of 1 to 5 support the findings of [2] that said: "telenursing is technically feasible, well-accepted by patients and helpful for patients with bulimia nervosa to readjust to everyday life after finishing inpatient treatment”. 


\section{Conclusion and Recommendation}

\section{A. Discussion of findings}

This research implemented a mobile telenursing system which was made available to nursing personnel via Mobile and SMS platform using android technology. It is an attractive system of delivering nursing services to patients without the need for both the patient and nurses to be in the same location at the same time. It has a major role in providing remote drug usage monitoring and after treatment nursing care to patients, fills a service gap among those that have limited access to nursing care and provides guided self-care to patients thereby reducing patients' visit to a hospital facility.

The performance of the MTS which was evaluated through user experience showed that:

i) the nurses had confidence in the ability of the MTS as being suitable telenursing system to function in the many capacities including drug usage monitoring, remote nursing care provision, triage, patient's education, palliative care provision, patient's monitoring and after treatment, etc. in developing countries. However, the developed system was not found suitable to be used to direct on injection administration and patients clean up.

ii) The MTS is an effective complement to traditional nursing care to provide drug usage adherence, remote nursing care, triage, patient's evaluation, and remote evaluation and prescription, patient's education, monitoring and after treatment, etc.

iii) In terms of usability/acceptability, the MTS was found to be acceptable in terms of its cost of implementation, training requirement, and ease of interpreting patient's clinical condition, etc. even though its acceptability in terms of ease of interpretation of nursing care needs and requirement of information technology technical-know-how by users were not as acceptable as other factors.

\section{B. Recommendation}

In view of the findings in this study, the following recommendations were made:

i) The research work does not make use of real-time monitoring devices (e.g. real-time blood pressure and temperature monitoring device), thus, subsequent research may need to include this.

ii) The developed system was shown not to be suitable for patients' education, injection administration and cleanup of patients hence, subsequent works can be done on improving the mobile nursing system to be suitable for this purpose.

iii) The MTS does not allow relaying of vital signs via visual means; thus, further implementation may need to include this.

iv) Due to the suitability, effectiveness, acceptability, and ease of usage of the developed system and its affordability to both nurses and patients, there is a need to massively embrace the system by the nurses especially in developing countries like Nigeria.

Table 2. Suitability of the developed system for mobile telenursing services

\begin{tabular}{|c|c|c|c|c|}
\hline Suitability Variables & Before T. I. & $\begin{array}{l}\text { After T. } \\
\quad \text { I. }\end{array}$ & $\begin{array}{l}\text { Correlation } \\
\text { value }(\mu)\end{array}$ & p-value \\
\hline $\begin{array}{ll}\text { Drug } & \text { usage } \\
\text { monitoring } & \end{array}$ & 2.96 & 3.63 & $0.656^{* *}$ & 0.00 \\
\hline Remote prescription & 2.96 & 3.75 & $0.829 * *$ & 0.00 \\
\hline Patients' education & 3.20 & 3.92 & 0.274 & 0.06 \\
\hline Triage & 2.42 & 3.29 & $0.933^{* *}$ & 0.00 \\
\hline $\begin{array}{l}\text { Injection } \\
\text { administration }\end{array}$ & 2.24 & 2.00 & $(0.772 * *)$ & 0.00 \\
\hline Palliative care & 2.71 & 3.63 & $0.925^{* *}$ & 0.00 \\
\hline Clean up of patients & 2.80 & 2.69 & $(0.841 * *)$ & 0.00 \\
\hline Drug usage reminder & 3.10 & 3.87 & $0.752 * *$ & 0.00 \\
\hline Patients' monitoring & 2.75 & 3.62 & $0.906^{* * *}$ & 0.00 \\
\hline $\begin{array}{ll}\begin{array}{l}\text { Patient's } \\
\text { treatment }\end{array} & \text { after } \\
\end{array}$ & 2.87 & 3.71 & $0.868 * *$ & 0.00 \\
\hline $\begin{array}{ll}\begin{array}{l}\text { Overall } \\
\text { suitability }\end{array} & \text { mean } \\
\end{array}$ & 2.97 & 3.57 & 0.837 & 0.00 \\
\hline
\end{tabular}


Table 3. Effectiveness of the developed system (nurses' perspectives)

\begin{tabular}{|c|c|c|c|c|}
\hline $\begin{array}{l}\text { Effectiveness } \\
\text { Variables }\end{array}$ & $\begin{array}{c}\text { Before T. } \\
\text { I. }\end{array}$ & $\begin{array}{l}\text { After } \\
\text { T. I. }\end{array}$ & $\begin{array}{c}\text { Mean difference } \\
(\mu)\end{array}$ & p-value \\
\hline $\begin{array}{ll}\text { Drug } & \text { usage } \\
\text { adherence } & \end{array}$ & 2.85 & 3.65 & 0.808 & 0.00 \\
\hline $\begin{array}{l}\text { Reduction of self- } \\
\text { medication }\end{array}$ & 2.69 & 3.55 & 0.863 & 0.00 \\
\hline $\begin{array}{l}\text { Enhancing patients' } \\
\text { education }\end{array}$ & 3.12 & 3.78 & 0.660 & 0.00 \\
\hline $\begin{array}{l}\text { Enhancing patient's } \\
\text { evaluation/prescript } \\
\text { ion }\end{array}$ & 2.64 & 3.44 & 0.800 & 0.00 \\
\hline $\begin{array}{l}\text { Enhancing patient's } \\
\text { after-treatment }\end{array}$ & 3.06 & 3.84 & 0.780 & 0.00 \\
\hline $\begin{array}{l}\text { Enhancing guided } \\
\text { patient self-care }\end{array}$ & 3.04 & 3.81 & 0.766 & 0.00 \\
\hline $\begin{array}{l}\text { Enhancing drug } \\
\text { administration } \\
\text { process }\end{array}$ & 2.79 & 3.60 & 0.813 & 0.00 \\
\hline $\begin{array}{l}\text { Reducing inpatients } \\
\text { in hospitals }\end{array}$ & 2.98 & 3.47 & 0.490 & 0.00 \\
\hline $\begin{array}{l}\text { Improving access to } \\
\text { nursing care }\end{array}$ & 2.82 & 3.51 & 0.694 & 0.00 \\
\hline $\begin{array}{l}\text { Enhancing } \\
\text { ubiquitous nursing } \\
\text { care }\end{array}$ & 3.18 & 3.76 & 0.571 & 0.00 \\
\hline $\begin{array}{l}\text { Overall mean } \\
\text { effectiveness }\end{array}$ & 2.72 & 3.59 & 0.87 & 0.00 \\
\hline $\begin{array}{l}\text { Effectiveness } \\
\text { Variables }\end{array}$ & $\begin{array}{l}\text { Before T. } \\
\text { I. }\end{array}$ & $\begin{array}{l}\text { After } \\
\text { T. I. }\end{array}$ & $\underset{(\mu)}{\text { Mean difference }}$ & p-value \\
\hline
\end{tabular}

Table 4. Effectiveness of the developed system (patients' perspectives)

\begin{tabular}{|l|c|c|c|c|}
\hline $\begin{array}{l}\text { Effectiveness } \\
\text { Variables }\end{array}$ & $\begin{array}{c}\text { Without T. } \\
\text { I. }\end{array}$ & With T. I. & $\begin{array}{c}\text { Mean } \\
\text { difference }(\boldsymbol{\mu})\end{array}$ & p-value \\
\hline $\begin{array}{l}\text { Drug usage } \\
\text { monitoring }\end{array}$ & 2.30 & 3.47 & 1.16 & 0.00 \\
\hline $\begin{array}{l}\text { Remote nursing } \\
\text { care }\end{array}$ & 2.21 & 3.43 & 1.23 & 0.00 \\
\hline $\begin{array}{l}\text { Enhancing patients' } \\
\text { education }\end{array}$ & 2.38 & 3.43 & 1.06 & 0.00 \\
\hline $\begin{array}{l}\text { Enhancing patient's } \\
\text { evaluation and } \\
\text { prescription usage }\end{array}$ & 1.91 & 3.27 & 1.35 & 0.00 \\
\hline $\begin{array}{l}\text { Drug } \\
\text { reminder }\end{array}$ & 2.12 & 3.17 & 1.05 & 0.00 \\
\hline $\begin{array}{l}\text { Enhancing patient's } \\
\text { after-treatment }\end{array}$ & 2.29 & 3.27 & 0.97 & 0.00 \\
\hline $\begin{array}{l}\text { Reduction of self- } \\
\text { medication }\end{array}$ & 2.45 & 3.25 & 0.80 & 0.00 \\
\hline $\begin{array}{l}\text { Enhancing guided } \\
\text { patient self-care }\end{array}$ & 2.22 & 3.28 & 1.06 & 0.00 \\
\hline $\begin{array}{l}\text { Assistance received } \\
\text { for } \\
\text { administration drug }\end{array}$ & 2.32 & 3.47 & 1.14 & 0.00 \\
\hline $\begin{array}{l}\text { Enhancing nursing } \\
\text { ubiquitous nare } \\
\text { care }\end{array}$ & 2.29 & 3.50 & 1.21 & 0.00 \\
\hline $\begin{array}{l}\text { Overall mean } \\
\text { effectiveness }\end{array}$ & $\mathbf{2 . 2 0}$ & $\mathbf{3 . 3 2}$ & $\mathbf{1 . 1 2}$ & $\mathbf{0 . 0 0}$ \\
\hline
\end{tabular}


Table 5. Usability and Acceptability of the developed system (nurses' perspectives)

\begin{tabular}{|c|c|c|c|c|}
\hline Usability Variables & $\begin{array}{l}\text { Before } \\
\text { T. I. }\end{array}$ & $\begin{array}{l}\text { After } \\
\text { T. I. }\end{array}$ & Mean difference & p-value \\
\hline $\begin{array}{l}\text { Negligibility of cost of } \\
\text { implementation }\end{array}$ & 2.72 & 3.91 & 1.191 & 0.00 \\
\hline Training requirement & 2.33 & 3.80 & 1.469 & 0.00 \\
\hline $\begin{array}{l}\text { Interpretation } \\
\text { nursing care needs }\end{array}$ & 2.63 & 3.85 & 1.229 & 0.00 \\
\hline $\begin{array}{l}\text { Monitoring drug usage } \\
\text { adherence }\end{array}$ & 2.43 & 3.82 & 1.388 & 0.00 \\
\hline $\begin{array}{l}\text { Requirement of } \\
\text { information technology } \\
\text { technical-know-how }\end{array}$ & 2.22 & 3.82 & 1.592 & 0.00 \\
\hline $\begin{array}{l}\text { Allowance for doctor's } \\
\text { input during diagnosis }\end{array}$ & 2.63 & 3.92 & 1.292 & 0.00 \\
\hline $\begin{array}{lr}\begin{array}{l}\text { Ease of } \\
\text { patients' } \\
\text { condition }\end{array} & \text { interpreting } \\
\end{array}$ & 2.67 & 3.54 & 0.875 & 0.00 \\
\hline $\begin{array}{l}\text { Benefits outweighing } \\
\text { implementation cost }\end{array}$ & 2.92 & 3.92 & 1.000 & 0.00 \\
\hline $\begin{array}{l}\text { Similarity with } \\
\text { traditional nursing }\end{array}$ & 2.40 & 3.91 & 1.511 & 0.00 \\
\hline $\begin{array}{l}\text { Objectivity } \\
\text { subjectivity }\end{array}$ & 3.06 & 3.96 & 0.898 & 0.00 \\
\hline $\begin{array}{ll}\begin{array}{l}\text { Overall } \\
\text { acceptability }\end{array} & \text { mean }\end{array}$ & 2.37 & 3.77 & 1.40 & 0.00 \\
\hline
\end{tabular}

Table 6. Usability and Acceptability of the developed system (patients' perspectives)

\begin{tabular}{|l|l|l|l|}
\hline Usability Variables & $\begin{array}{l}\text { After } \\
\text { T. I. }\end{array}$ & $\begin{array}{l}\text { Mean } \\
\text { difference }\end{array}$ & p-value \\
\hline Negligibility of cost of implementation & 3.60 & 0.60 & 0.00 \\
\hline Training requirement & 3.37 & 0.37 & 0.02 \\
\hline Interpretation of nursing care needs & 3.07 & 0.07 & 0.60 \\
\hline Monitoring drug usage adherence & 3.53 & 0.53 & 0.00 \\
\hline $\begin{array}{l}\text { Requirement of information technology } \\
\text { technical-know-how }\end{array}$ & 3.03 & 0.03 & 0.79 \\
\hline Allowance for doctor's input during diagnosis & 3.27 & 0.27 & 0.04 \\
\hline Ease of interpreting patients' clinical condition & 3.30 & 0.30 & 0.00 \\
\hline Benefits outweighing implementation cost & 3.70 & 0.70 & 0.00 \\
\hline Similarity with traditional nursing & 3.30 & 0.30 & 0.00 \\
\hline Objectivity versus subjectivity & 3.42 & 0.42 & 0.00 \\
\hline Overall mean acceptability & $\mathbf{3 . 3 6}$ & $\mathbf{1 . 1 1}$ & $\mathbf{0 . 0 0}$ \\
\hline
\end{tabular}

\section{References}

[1] J. O. Adigun, J. O. Onihunwa, D. A. Joshua, \& O. O. Adesina, Framework for development of mobile telenursing system for developing countries. 13th International Conference of the Nigeria Computer Society (pp. 41-54). Lagos, Nigeria: Nigeria Computer Society (NCS), 2017

[2] S. Bauer, R. Percevic, R., H., and Kordy. The use of short message service (SMS) in the aftercare treatment for patients with Bulimia Nervosa. 2009, www.medetel.lu/download/2009/parallel_sessions/abstract/0422/ the_use_of_ short_message_service.doc

[3] Gustafsson-Wright Emily and Schellekens Onno. Achieving Universal Health Coverage in Nigeria: one state at a time a publicprivate partnership community-based health insurance model. Brooke Shearer Working Paper series. Global Economy and Development at the Brookings Institution. 2018, www..brookings.edu/research/2016/06.

[4] Edel, Elizabeth M. "Handbook of Informatics for Nurses \& Healthcare Professionals." Aorn Journal 90, no. 1 (2009): $139-140$. 
[5] M. Jordanova, M. "m-Health, mHealth, or Mobile Health-which one is correct? Mobile eHealth solutions for Developing Countries." International Telecommunication Union (2009): 1-4.

[6] Purc-Stevenson R. J., Telenursing: A Review of Recent Trends, Emerging Issues, and Evolving Practices. Mary Ann Liebert, Journal of telemedicine and e-health publications. 2013; 1(2):6-11,2013

[7] Ramelet Anne-Sylvie, Fonjallaz B., Rapin J., Gueniat C. and Hofer M. Impact of a Telenursing service on satisfaction and health outcomes of children with inflammatory rheumatic diseases and their families: a crossover randomized trial study protocol. 2014

[8] Schlachta-Fairchild L., Elfrink V. and Delchman A. Patient safety, Telenursing and telehealth - Patient safety and quality NCBI bookshelf 2009 www.ncbi.nim.nih.gov/books/NBK2687

[9] Schwaab B, Katalinic A, Riedel J and Sheikhzadeh A. Pre-hospital diagnosis of myocardial ischemia by telecardiology: Safety and efficacy of a 12-lead electrocardiogram, recorded and transmitted by the patient. Journal of Telemed Telecare 2005;11(1):41-4.

[10] Villani A, Malfatto G, Compare A, Della R. F., and Rella V. Clinical and Psycological Telemonitoring and Telecare of High Risk Patients with Chronic Heart Failure through Wireless Technologies: The Icaros Project. Journal of Clin Exp Cardiolog 4: 260. doi:10.4172/2155-9880.1000260, 2013G. Eason, B. Noble, and I. N. Sneddon, "On certain integrals of Lipschitz-Hankel type involving products of Bessel functions," Phil. Trans. Roy. Soc. London, vol. A247, pp. 529-551, April 1955.

\section{Authors' Profiles}

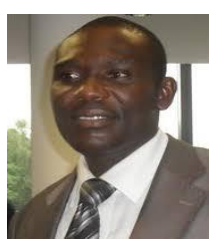

Justice Emuoyibofarhe is a Professor of Computing at Ladoke Akintola University of Technology. He received his $\mathrm{PhD}$ in 2004. He specialises in neuro-fuzzy computing computational optimisation. He had post-doctoral fellowship at the Centre of Excellence for Mobile e-service, University of Zululand, South Africa in 2006. He is a member of the IEEE Computational Intelligence Society. He is also a Visiting Researcher at the Hasso Plattner Institute, University of Potsdam, Germany. His present research area is in the application of mobile computing and wireless communication to e-health and telemedicine.

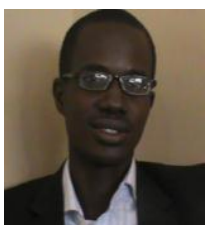

Adigun J. Olusegun studied Computer Science and Engineering with specialization in Computer Science and graduated with a BTECH (Hons) from Ladoke Akintola University of Technology in 2008, obtained a Masters' degree (Mtech., Computer Science) from the same university in 2018. He has had work experience with Forestry Research Institute of Nigeria as a Senior Programme Analyst and is currently a lecturer at the Federal College of Wildlife Management, New Bussa. He had a one year intensive training as a professional teacher at Federal College of Education (Special), Oyo in 2016 and has a Professional Diploma in Special Education. His research interest includes Computer Science education and Human Computer Interaction and is more fascinated about

Special Education.

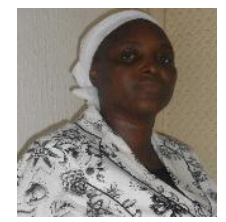

Dr. Mrs. Emuoyibofarhe Ozichi received her Ph.D in 2014 from the Federal University of Technology, Minna Her Research interest include Computer Science, Mathematical modeling of Epidemiological Data. She is currently a Senior Lecturer at the Department of Computer Science and Information Technology. Bowen University Iwo. She had her Post doctoral fellowship at the Hasso Plattner Institut, University of Potsdam, Germany.

How to cite this paper: Emuoyibofarhe O. Justice, Adigun J. Olusegun, Emuoyiborfarhe N. Ozichi, " Development and Evaluation of Mobile Telenursing System for Drug Administration", International Journal of Information Engineering and Electronic Business(IJIEEB), Vol.12, No.4, pp. 40-52, 2020. DOI: 10.5815/ijieeb.2020.04.05 